\title{
Utility of a Nurse-Led Pathway for Patients with Acute Venous Thromboembolism Discharged on Rivaroxaban: A Prospective Cohort Study
}

\author{
Ming Sheng Lim, MBBS, BMedSCi, FRACP, FRCPA ${ }^{1}$ Tishya Indran, MBBS, FRACP, FRCPA ${ }^{1}$ Anita Cummins ${ }^{1}$ \\ Ashwini Bennett, MBBS, FRACP, FRCPA ${ }^{1}$ Erica Wood, MBBS, FRACP, FRCPA ${ }^{1,3}$ \\ Susan Brown, MBBS, PhD, FRACP, FRCPA ${ }^{1}$ Zoe McQuilten, MBBS, PhD, FRACP, FRCPA 1,3 \\ Huyen Tran, MBBS, Master Clin Epi, FRACP, FRCPA ${ }^{4,5}$ Noel C. Chan, MBBS, FRACP, FRCPA ${ }^{6,7}$ \\ Sanjeev Chunilal, MB ChB, FRACP, FRCPA ${ }^{1,2}$
}

${ }^{1}$ Department of Hematology, Monash Medical Centre, Monash Health, Clayton, Victoria, Australia

2 Faculty of Medicine Nursing and Health Science, Monash University, Melbourne, Victoria, Australia

${ }^{3}$ Transfusion Research Unit, School of Public Health and Preventive

Medicine, Monash University, Melbourne, Victoria, Australia

${ }^{4}$ The Australian Centre for Blood Diseases, Monash University, Alfred

Medical Research and Educational Precinct, Melbourne, Australia

${ }^{5}$ Department of Clinical Hematology, The Alfred Hospital,

Melbourne, Australia

6 Thrombosis and Atherosclerosis Research Institute, McMaster

University, Hamilton, Ontario, Canada

${ }^{7}$ Department of Medicine, McMaster University, Hamilton, Ontario, Canada
Address for correspondence Ming Sheng Lim, FRACP, FRCPA, MBBS, BMedSci, Department of Haematology, Monash Medical Centre, Level 4 Monash Medical Centre, 246 Clayton Road, Clayton, Victoria 3168, Australia (e-mail: mingsheng.lim@monashhealth.org).

Semin Thromb Hemost 2019;45:187-195.

The highest risk of adverse events for patients with acute venous thromboembolism (VTE) is during the early anticoagulation period. However, no established model exists for early clinical monitoring of patients treated with non-vitamin $\mathrm{K}$ antagonist oral anticoagulants (NOACs). The authors' aim was to evaluate the utility of a nurse-led pathway to minimize adverse events in acute VTE patients starting on rivaroxaban. The rivaroxaban VTE treatment pathway is a prospective cohort study of consecutive patients with objectively confirmed VTE between July 2015 and May 2017. Primary outcome was the proportion of patients identified at major risk of adverse events (bleeding or recurrent VTE). Secondary outcomes were rates of interventions, major or clinically relevant nonmajor bleeding (CRNMB), recurrent VTE, and all-cause mortality at 90 days. Among 304 participants, 5\% ( $n=15)$ were identified to be at major and $9 \%(n=28)$ at possible risk for adverse events. Appropriate interventions to prevent harm were required in 40 patients. Rates of major bleeding, CRNMB, recurrence, and all-cause mortality were $0.3 \%$ (95\% confidence interval [Cl]: 0.1-1.8), 7.2\% (95\% Cl: 4.8-10.7), 1.0 (95\% Cl: 0.3-2.9), and 1.6\% (95\% Cl: 0.7-3.8), respectively. In conclusion, following discharge of acute VTE patients, a nurse-led pathway identified one in seven (14\%) patients at major or possible risk of adverse events. Preemptive interventions to reduce harm translated into the low rates of bleeding and recurrence. The authors' experience highlights the feasibility and importance of a structured clinical surveillance pathway for acute VTE patients initiating NOAC therapy.
- adverse drug event thromboembolism
Copyright (c) 2019 by Thieme Medical Publishers, Inc., 333 Seventh Avenue, New York, NY 10001, USA. Tel: +1(212) 584-4662.
DOI https://doi.org/ 10.1055/s-0038-1676320. ISSN 0094-6176. 
Venous thromboembolism (VTE), comprising deep vein thrombosis (DVT) and pulmonary embolism (PE), is common with an annual incidence of 1 per 1,000 in Caucasian adults ${ }^{1}$ and results in a major burden to the healthcare system. The mainstay of treatment for VTE over recent decades has been initial anticoagulation with heparin or low-molecular-weight heparin (LMWH) followed by vitamin K antagonist (VKA).

The non-vitamin $\mathrm{K}$ antagonist oral anticoagulants (NOACs) have provided an effective, safe, and convenient alternative to VKA, ${ }^{2}$ which has led to their increasing use. ${ }^{3}$ Rivaroxaban, a factor Xa inhibitor, is approved as monotherapy for the initial treatment of acute VTE. This has simplified the treatment of patients with acute VTE and facilitated early discharge from hospital. Anticoagulants, including NOACs, remain the most common drug class implicated in adverse drug-related events prompting presentations to emergency departments (ED). ${ }^{4}$ Data from the phase 3 clinical trials comparing the safety and efficacy of NOACs to VKA/LMWH have shown that rates of bleeding and VTE recurrence are highest during the first few weeks of anticoagulation therapy, ${ }^{5-10}$ highlighting the potential benefit of careful patient monitoring early during the anticoagulation period.

Although the use of VKAs with daily injections of LMWH and international normalized ratio (INR) monitoring provided opportunities for early detection and prevention of adverse events because of the regular contact with health care professionals, such "informal" monitoring has been significantly reduced with the NOACs. Although randomized trials showed favorable outcomes with the use of NOACs, commencement of NOAC therapy can be problematic outside of the controlled environment of clinical trials. Indeed published surveys report up to a third of hospital patients may receive an incorrect dose or are inappropriately prescribed a NOAC even when contraindicated. ${ }^{11-14}$

The International Society on Thrombosis and Haemostasis $(\text { ISTH })^{15}$ and European Heart Rhythm Association (EHRA) ${ }^{16}$ provide practical guidance on the use of NOACs, emphasizing the need for appropriate patient selection, minimizing unnecessary drug-drug interactions, and monitoring for dosing errors, adherence, or adverse effects. Several models of care for the optimal follow-up and clinical monitoring of patients receiving therapy with NOACs have been proposed, ${ }^{17}$ but there are currently no published studies evaluating the effectiveness of a nurse-led approach.

Monash Health, a major university metropolitan health service in Victoria, Australia, provides acute inpatient services at four campuses. Rivaroxaban was the first NOAC in Australia to receive approval for the treatment of VTE (August 2013) and was the only government-subsidized NOAC available for this indication in 2015 when our pathway was initiated. The overall aim for our pathway was to facilitate the safe transition of patients with VTE treated with rivaroxaban into the community. Our pragmatic pathway was designed to be coordinated by an experienced anticoagulation nurse with oversight by experienced hematologists, and to provide broad access to all patients within the large geographical area covered by our health service. We used simple and inexpensive methods of communication such as telephone contact and text messaging to achieve this goal.

The aims of this study were to report on (1) the proportion of patients who were identified as at risk for adverse events (i.e., bleeding or recurrence) using prespecified criteria, (2) the proportion of patients requiring interventions, and (3) the clinical outcomes (bleeding and recurrent thrombosis) of patients who were prospectively followed up and managed through our nurse-led postdischarge pathway.

\section{Methods}

\section{Study Design and Participants}

We prospectively followed up a cohort of consecutive patients with objectively confirmed acute VTE, who were enrolled in the rivaroxaban VTE treatment pathway between July 28, 2015, and May 31, 2017. This project was approved as a quality and service improvement project (reference number RES-17-0000-196Q). Patients were identified by screening pharmacy discharge scripts, inpatient admissions/consultations, referrals to the hematology outpatient clinic, or by ED discharge summaries. Patients were eligible for inclusion if they were at least 18 years of age, with objectively confirmed acute VTE and who were initiated on rivaroxaban. Patients with superficial vein thrombosis/or venous thrombosis in any vascular territory were included in our definition of VTE. Exclusion criterion was anticoagulation for other indications, for example, stroke prevention for atrial fibrillation or thromboprophylaxis post-hip/knee arthroplasty.

\section{Study Procedures/Data Collection}

An overview of the pathway is shown in -Fig. 1. In brief, an experienced research nurse (AC) extracted relevant clinical and laboratory information for review by the anticoagulation team within 10 to 14 days of discharge. The team consisted of the research nurse, one hematology fellow, and two hematologists. Subsequently, patients were followed up by the study nurse with telephone calls and/or text messaging at 14 , $21,35,45$, and 90 days to monitor for any bleeding, VTE recurrence, patient adherence, appropriate dosing, concomitant medications, and laboratory parameters. These data were recorded on prespecified checklists at each contact (-Supplementary Fig. S1, online only). Duration of follow-up was up to 90 days or until end of treatment or death whichever came earlier. A patient information kit was also mailed within a week of the first telephone call, containing a rivaroxaban information booklet; an emergency contact card; and a laboratory request form for complete blood count $(\mathrm{CBC})$, urea, electrolytes and creatinine (UEC), and liver function test (LFT). Patients on the pathway were routinely reviewed as an outpatient within 30 to 60 days.

If a patient was identified as being at risk of bleeding or recurrent thrombosis, then appropriate measures (interventions) were undertaken to mitigate their risk of harm. Most interventions, where deemed appropriate, were performed by telephone instructions to the patient, their family, family physician, or pharmacist to minimize need for healthcare 


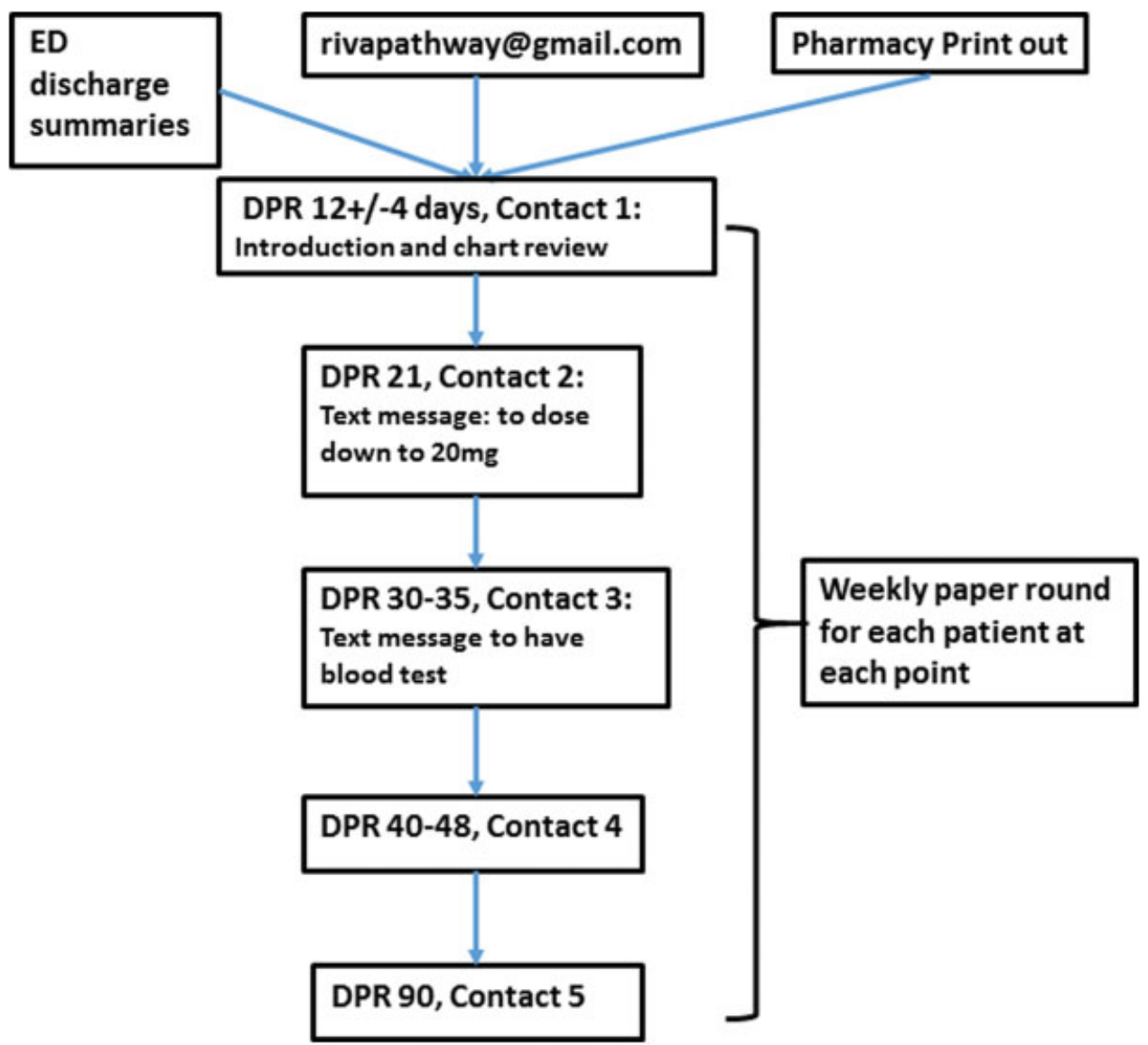

Fig. 1 Overview of nurse-led rivaroxaban pathway at Monash Health. During each contact, patients are assessed for bleeding, VTE recurrence, nonadherence, and appropriate dosing. DPR, days post rivaroxaban; ED, emergency department; VTE, venous thromboembolism.

facility visits. However, clinical review or ED visits were organized when required.

\section{Study Outcomes}

The primary outcome was the proportion of patients at major risk of bleeding or VTE recurrence post-hospital discharge using prespecified criteria. These criteria were based on the exclusion criteria and recommended doses used in the pivotal phase 3 trials evaluating use of rivaroxaban for acute VTE treatment (-Table 1). ${ }^{5,6}$ Secondary outcomes were (1) the proportion of patients with other prespecified risk factors for bleeding/ recurrence, (2) proportion of patients requiring major or minor interventions, and (3) rates of major or clinically relevant nonmajor bleeding (CRNMB), objectively confirmed recurrent VTE, all-cause mortality, and non-bleeding-related rehospitalization at 90 days from the time of enrolment into the study.

\section{Study Definitions}

Major bleeding and CRNMB were as defined by the ISTH. ${ }^{18,19}$ Recurrent VTE was defined as new or progression of thrombus from baseline ultrasound for DVT or new/extension of filling defects on computed tomography pulmonary angiogram (CTPA) or new mismatches on ventilation-perfusion (VQ) scan in a patient with new or worsening symptoms. A major intervention was any intervention requiring unscheduled inpatient admission/ED attendance or clinic review.
Minor interventions were any other interventions not requiring hospital/clinic visit. Interventions were categorized according to hospital resource utilization but not necessarily weighted by their clinical importance. For example, if the nurse identified a patient taking an incorrect dose of rivaroxaban, this patient was deemed at "major risk" for an adverse event, but if this was managed by simple telephone instructions or provision of a new prescription, the intervention was considered "minor" despite the potential for significant harm to the patient.

Minimum baseline bloods were defined as $C B C$, serum creatinine, LFTs, and routine coagulation testing (activated partial thromboplastin time, INR, and fibrinogen level) prior to commencement of rivaroxaban. Creatinine clearance $(\mathrm{CrCl})$ was based on the Cockcroft Gault equation using actual body weight.

\section{Statistical Analysis}

Descriptive statistics were used to analyze patient demographics and baseline data using Microsoft Excel 2013. Categorical variables are expressed as frequency and percentage with $95 \%$ confidence interval (CI); continuous variables are expressed as mean and standard deviation. The 95\% CIs of proportions were calculated using the Wilson Score method (online calculator available at http://epitools.ausvet.com.au/ content.php). 
Table 1 Prespecified risk factors for intervention

\begin{tabular}{|c|c|}
\hline Risk category & Criteria \\
\hline \multirow{5}{*}{$\begin{array}{l}\text { Major risk } \\
\text { of bleeding }\end{array}$} & Renal impairment $\mathrm{CrCl}$ or eGFR ${ }^{\mathrm{a}}<30-40 \mathrm{~mL} / \mathrm{min}$ \\
\hline & Higher than recommended dose ${ }^{b}$ at any time \\
\hline & Use of strong CYP 3A4 or P-glycoprotein inhibitors and $\mathrm{CrCl}$ or eGFR $30-50 \mathrm{~mL} / \mathrm{min}$ \\
\hline & Weight $<50 \mathrm{~kg}$ \\
\hline & Thrombocytopenia $<50 \times 10^{9} / \mathrm{L}$ \\
\hline \multirow{5}{*}{$\begin{array}{l}\text { Possible risk } \\
\text { of bleeding }\end{array}$} & Thrombocytopenia $50-80 \times 10^{9} / \mathrm{L}$ \\
\hline & Evidence of coagulopathy INR/PT/APTT $>1.5$ times upper limit of normal or fibrinogen $<2.0$ \\
\hline & $\begin{array}{l}\text { Recent history of gastrointestinal bleeding, intracranial bleeding, or bleed into a critical } \\
\text { organ in the last } 12 \text { weeks, history of angiodysplasia, gastric ulcers, or menorrhagia }\end{array}$ \\
\hline & Thrombocytopenia 50-80 $\times 10^{9} / \mathrm{L}$ and concomitant antiplatelet therapy \\
\hline & Uncontrolled hypertension (systolic BP $>180$ or diastolic BP $>110 \mathrm{~mm} \mathrm{Hg}$ ) \\
\hline \multirow{2}{*}{$\begin{array}{l}\text { Major risk of } \\
\text { VTE recurrence }\end{array}$} & Incomplete treatment course, i.e., inadequate duration or lower than recommended dose ${ }^{\mathrm{b}}$ \\
\hline & Weight $>150 \mathrm{~kg}$ \\
\hline \multirow{2}{*}{$\begin{array}{l}\text { Possible risk } \\
\text { of VTE } \\
\text { recurrence }\end{array}$} & Weight $>120 \mathrm{~kg}$ or BMI $>40 \mathrm{~kg} / \mathrm{m}^{2}$ \\
\hline & Use of strong inducers of CYP3A4 \\
\hline \multirow{2}{*}{$\begin{array}{l}\text { Uncertain risk } \\
\text { of recurrence }\end{array}$} & Cancer/antiphospholipid syndrome \\
\hline & $\begin{array}{l}\text { Interruption to treatment, e.g., nausea or vomiting, temporary cessation of anticoagulation } \\
\text { for elective surgical procedure }\end{array}$ \\
\hline
\end{tabular}

Abbreviations: APTT, activated partial thromboplastin time; BMI, body mass index; BP, blood pressure; $\mathrm{CrCl}$, creatinine clearance based on the Cockcroft Gault equation; eGFR, estimated glomerular filtration rate; INR, international normalized ratio; PT, prothrombin time; VTE, venous thromboembolism.

a eGFR was used if unable to calculate creatinine clearance due to missing information. A lower threshold of $30-40 \mathrm{~mL} / \mathrm{min}$ was considered a risk factor for bleeding as a safe precaution taking into consideration daily fluctuation in $\mathrm{Cr}$.

${ }^{\mathrm{b}} 15 \mathrm{mg}$ twice daily for first 3 weeks and $20 \mathrm{mg}$ daily thereafter.

\section{Role of the Funding Source}

The study was supported by a sponsorship grant by Bayer Australia. The sponsor had no role in the design, conduct, or analysis of the study, manuscript preparation, or decision to submit the manuscript for publication.

\section{Results}

\section{Characteristics of Study Cohort}

Between July 28, 2015, and May 31, 2017, a total of 341 patients were identified in the pathway. After exclusion of 10 patients, 331 patients were eligible for analysis of primary and secondary outcomes (-Fig. 2). The pathway had to be suspended from December 15, 2016, to January 31, 2017, due to an illness in a member of the study team. During this period, 27 patients were identified but not followed up according to the study protocol timelines and therefore were excluded in the analysis. However, their follow-up outcomes are available and are reported separately (-Supplementary Table S1, online only).

Of the 304 patients included, median age was 56 years with equal proportions of males and females. PE (with or without DVT) was diagnosed in 178 (58.5\%) patients, 53 (17.4\%) patients had a proximal DVT, and 62 (20.4\%) had a distal DVT. Other indications for anticoagulation were upper limb DVT $(n=5)$, superficial vein thrombosis $(n=4)$, internal jugular vein thrombosis $(n=1)$, and portal vein thrombosis $(n=1)$. Hereditary thrombophilia was not routinely evaluated. However, 16 patients had documented thrombophilia (12 heterozygous FV Leiden mutation, 1 antithrombin deficiency, 1 homozygous prothrombin mutation, 1 protein $C$ deficiency, and 1 heterozygous prothrombin mutation). Baseline characteristics of the patients are shown in - Table 2 .

\section{Treatment and Follow-up}

At 90 days, a total of 257 patients (85\%) remained on anticoagulation. Of these, 231 (74\%) remained on rivaroxaban therapy and 26 (10\%) were switched from rivaroxaban to another anticoagulant (warfarin $n=4$, enoxaparin $n=11$, apixaban $n=11$ ). The most common reasons for switching were concerns regarding bleeding or recurrence (-Supplementary Table S2, online only). In the other 47 patients, follow-up was less than 90 days due to death $(n=5)$ or treatment cessation earlier than 90 days $(n=34$ for distal DVT; $n=3$ for superficial vein thrombosis, and $n=5$ for proximal DVT/PE). Patients with PE or proximal DVT were on anticoagulant therapy for a median of 90 days (interquartile range [IQR]: 90-90 days), whereas patients with isolated distal DVT were on anticoagulant therapy for a median of 86 days (IQR: 47.5-90 days). All 304 patients were followed up to 90 days or until the end of treatment or death whichever occurred earlier. 


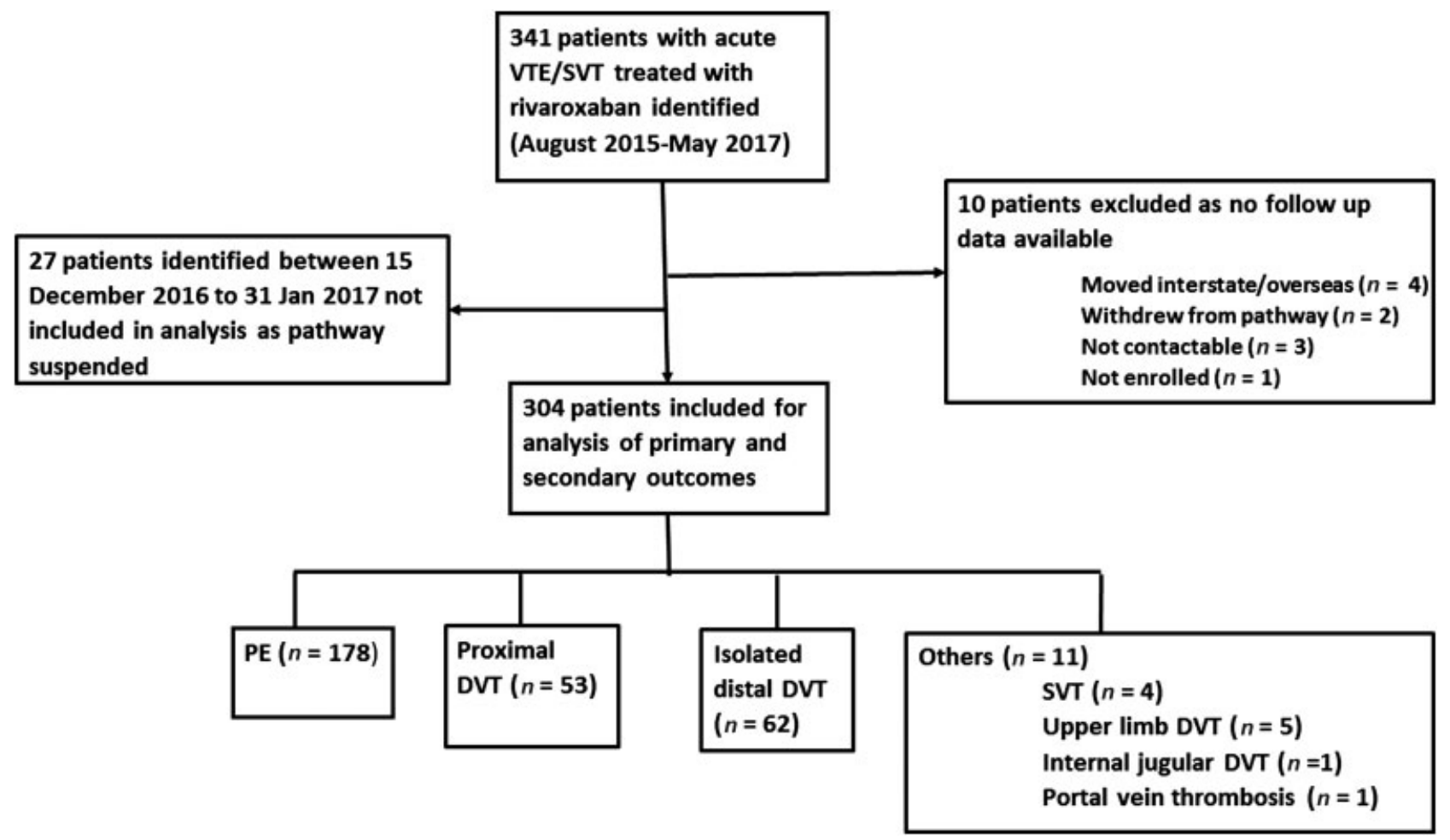

Fig. 2 Flow diagram of study cohort. DVT, deep vein thrombosis; PE, pulmonary embolism; SVT, superficial vein thrombosis; VTE, venous thromboembolism.

\section{Primary Outcome}

Fifteen of 304 patients (4.9\%; 95\% CI: 3.0-8.0) were identified to be at major risk of bleeding or recurrence. The most common major risks identified in patients were nonadherence ( $n=2)$ and taking a higher or lower than recommended dose of rivaroxaban ( $n=9$; - Table 3 ).

\section{Secondary Outcomes}

Proportion of patients with prespecified possible risk factors for bleeding or recurrence: Twenty-eight patients (9.3\%) were identified with prespecified possible risk factors for bleeding/recurrence including patients with previous gastrointestinal (GI) bleeding $(n=2)$, young women with known menorrhagia $(n=6)$, or patients with a body mass index (BMI) of greater than 40 or weight greater than $120 \mathrm{~kg}$ ( $n=14$; - Table 3 ).

\section{Proportion of Patients with Interventions}

Interventions were required for 167 patients in the entire cohort (54.9\%; 95\% CI: 49.3-60.4). Of the 43 patients with prespecified criteria, 40 had interventions of which 6 were major and 34 were minor. None of the patients with prespecified major risk factors suffered recurrent VTE or bleeding after appropriate interventions were instituted. Of the 28 patients with prespecified possible risk factors, recurrence was diagnosed in 1 patient with increased BMI of 42 and CRNMB occurred in 9 patients. The majority (five of nine) of these patients with CRNMB had worsening of preexisting menorrhagia (-Supplementary Table S2, online only). An additional 127 patients had interventions outside of pre- specified criteria of which 8 were major and 119 were minor (-Supplementary Table S3, online only). Twenty-eight patients were on concomitant medications that could increase the risk of bleeding including antiplatelet agents $(n=21)$ or fish oil, an inhibitor of platelet aggregation $(n=7)$. In patients on antiplatelets without clear indication $(n=12)$ or fish oil $(n=7)$, it was recommended to the patients or their general practitioner for these to be ceased to minimize the risk of bleeding.

\section{Clinical Outcomes}

Bleeding: Major bleeding occurred in one patient $(0.3 \%$; $95 \%$ CI: 0.1-1.8), who suffered from an upper GI bleed. CRNMB was observed in 22 patients (7.2\%; 95\% CI: 4.8-10.7). The most common sites of CRNMB bleeding were genitourinary $(n=10)$ and GI $(n=6)$. Most bleeding events $(15 / 23,65 \%)$ occurred in the first month of anticoagulation (-Supplementary Fig. S2, online only).

Recurrent VTE: Recurrent VTE occurred in three patients (1.0\%; 95\% CI: 0.3-2.9). All three cases of possible VTE recurrences occurred after the first month (-Supplementary Fig. S3, online only). Two patients had distal DVT recurrences while on rivaroxaban (for PE and distal DVT, respectively). One patient was diagnosed with a "new" PE on VQ scan 3 weeks after rivaroxaban was discontinued based on a nondiagnostic scan and was recommenced on anticoagulation by the treating clinicians without further definitive investigations. There were no patients with fatal PE.

Mortality: The incidence of all-cause mortality was 5 of 304 (1.6\%; 95\% CI: 0.7-3.8\%). 
Table 2 Baseline characteristics of study cohort $(n=304)$

\begin{tabular}{|c|c|}
\hline Characteristics & \\
\hline Age, y, median (IQR) & $56(44-70)$ \\
\hline Age $\geq 75$ y, $n(\%)$ & $54(17.8)$ \\
\hline Male sex, $n(\%)$ & $152(50.0)$ \\
\hline \multicolumn{2}{|l|}{ Weight, $n(\%)$} \\
\hline$<50 \mathrm{~kg}$ & $4(1.3)$ \\
\hline$\geq 50-100 \mathrm{~kg}$ & $201(66.1)$ \\
\hline$>100-120 \mathrm{~kg}$ & $45(14.8)$ \\
\hline$>120 \mathrm{~kg}$ & $8(2.6)$ \\
\hline Missing data & $46(15.2)$ \\
\hline \multicolumn{2}{|l|}{ Creatinine clearance, $\mathrm{mL} / \mathrm{min}^{\mathrm{a}}$} \\
\hline$<30$ & $0(0)$ \\
\hline 30 to $<50$ & $5(1.6)$ \\
\hline$\geq 50$ to $\leq 80$ & $60(19.7)$ \\
\hline$>80$ & $185(60.9)$ \\
\hline Missing data & $54(17.8)$ \\
\hline Provoked, $n(\%)$ & $167(54.9)$ \\
\hline Unprovoked, $n$ (\%) & $137(45.0)$ \\
\hline \multicolumn{2}{|l|}{ Indication, $n(\%)$} \\
\hline $\mathrm{PE}^{\mathrm{b}}$ & $178(58.5)$ \\
\hline Isolated lower limb distal DVT & $62(20.4)$ \\
\hline Lower limb proximal DVT ${ }^{\mathrm{b}}$ & $53(17.4)$ \\
\hline Upper limb DVT & $5(1.6)$ \\
\hline Internal jugular DVT & $1(0.3)$ \\
\hline Superficial vein thrombosis & $4(1.3)$ \\
\hline Portal vein thrombosis & $1(0.3)$ \\
\hline Prior VTE, $n$ (\%) & $58(19.1)$ \\
\hline Previous major bleeding, $n(\%)$ & $4(1.3)$ \\
\hline Known thrombophilia, $n$ (\%) & $16(5.3 \%)$ \\
\hline
\end{tabular}

Abbreviations: DVT, deep vein thrombosis; IQR, interquartile range; PE, pulmonary embolism; SVT, superficial vein thrombosis; VTE, venous thromboembolism.

${ }^{a}$ Serum creatinine result at or closest to and within 4 weeks of initiation of rivaroxaban was used for the calculation of creatinine clearance derived by the Cockcroft Gault equation based on actual body weight. bPatients with both PE/DVT were categorized as PE, patients with proximal and distal PE were categorized as proximal DVT.

Rehospitalization: Rehospitalization occurred in 22 of 304 (7.2\%; 95\% CI: 4.8-10.7). Five patients (1.6\%) required hospital admission due to bleeding/VTE recurrence, while the other 17 patients were admitted for other reasons.

\section{Discussion}

Our study demonstrates that at least 1 in 7 (43 of 304) patients prescribed rivaroxaban for acute VTE are at major or possible risk of adverse events following initiation of rivaroxaban in hospital. By early postdischarge identification of these "at-risk" patients, we were able to initiate appropriate interventions, which in the majority of patients entailed reinforcing medication adherence, clarifying the appropriate dosage, or occasionally switching anticoagulation therapy. We showed that these simple and timely interventions, coupled with an active program of regular monitoring using telephone calls and text-messaging reminders, were associated with low rates of major bleeding or recurrent VTE. Although examples of nurse-led VTE post-discharge pathway care have been described previously, ${ }^{20}$ to our knowledge, this is the first prospective study to comprehensively report on outcomes and the associated interventions in patients with acute VTE taking rivaroxaban.

\section{Rates of Bleeding and VTE Recurrence}

The rate of major bleeding $(0.3 \%$; $95 \% \mathrm{CI}$ : $0.1-1.8)$ with our nurse-led pathway is among the lowest reported in other observational studies. These studies reported rates of major bleeding which vary between 0.5 and $4 \%$ (-Table 5). 5,6,21-27 Higher rates of major bleeding (4.1\% per annum) were observed in the Dresden registry ${ }^{21}$ compared with the XALIA (XA inhibition with rivaroxaban for Long-term and Initial Anticoagulation in venous thromboembolism) study, ${ }^{25}$ which had lower rates of bleeding (1.2\% per annum). This difference is partly explained by younger patients in the XALIA study (74 vs. 59 years) and a lower proportion with impaired renal function ( 11 vs. $4 \%$ had glomerular filtration rate or $\mathrm{CrCl}<50 \mathrm{~mL} / \mathrm{min})$. However, another potential explanation is that unlike the Dresden registry, patients in XALIA were managed by experienced clinicians with a structured follow-up. Taken together, this suggests that appropriate patient selection and a post-discharge clinical monitoring are important to maximize the safety and efficacy benefits of rivaroxaban in clinical practice.

\section{Risk Factors for Bleeding or Recurrence}

In our study, we identified 3\% (10 of 304) of patients who were prescribed or taking the incorrect dose of rivaroxaban. However, this has been reported to be as high as 10 to $20 \%$ in other studies. ${ }^{13,28,29}$ We demonstrated that these patients could be identified quickly through our nurse-led pathway and that timely corrective action and education were easily instituted by telephone.

Major bleeding occurred in one patient secondary to an upper GI bleed due to gastric erosions. This patient had a history of iron deficiency for which multiple GI endoscopies had not identified a source of bleeding. She was switched empirically to apixaban 4 weeks previously (in view of nonspecific abdominal pain while taking rivaroxaban), which was discontinued at the time of the bleed. After bleeding had stabilized, the patient was commenced on enoxaparin.

Five of six women who presented with CRNMB secondary to heavy menstrual bleeding had a history of menorrhagia. Given the reported association of abnormal uterine bleeding with rivaroxaban, ${ }^{30,31}$ we specifically counseled these women on the risk of worsening menstrual bleeding and gave them the option to switch to anticoagulation but most 
Table 3 Patients with prespecified risk factors for bleeding/recurrence and interventions performed

\begin{tabular}{|c|c|c|c|c|}
\hline Risk category & Number & $\begin{array}{l}\text { Proportion \% } \\
(95 \% \mathrm{Cl})\end{array}$ & Risk factor ${ }^{a}$ & Interventions \\
\hline $\begin{array}{l}\text { Major risk } \\
\text { of bleeding }\end{array}$ & $6 / 304$ & $2.0(0.9,4.2)$ & $\begin{array}{l}\mathrm{CrCl}<30-40 \mathrm{~mL} / \mathrm{min}^{\mathrm{b}} \\
(n=2), \text { higher than recommended } \\
\text { dose }(n=2), \text { weight }<50 \mathrm{~kg} \\
(n=2)\end{array}$ & \multirow{6}{*}{$\begin{array}{l}\text { Major: hospital admissions/early clinic } \\
\text { review }(n=6) \\
\text { Minor: changed to correct dose/reinforced } \\
\text { medication adherence }(n=10) \\
\text { Minor: education, reassurance, } \\
\text { organizing laboratory tests }(n=24) \\
\text { Nil intervention }(n=3)\end{array}$} \\
\hline $\begin{array}{l}\text { Major risk } \\
\text { of recurrence }\end{array}$ & $9 / 304$ & $3.0(1.6,5.5)$ & $\begin{array}{l}\text { Nonadherence }(n=2) \text { lower than } \\
\text { recommended dose }(n=7)\end{array}$ & \\
\hline $\begin{array}{l}\text { Possible risk } \\
\text { of bleeding }\end{array}$ & $10 / 304$ & $3.3(1.8,6.0)$ & $\begin{array}{l}\text { History of menorrhagia }(n=6) \text {, } \\
\text { recent Gl bleed }(n=2) \text {, } \\
\text { thrombocytopenia } 50-80 \times 10^{9} / \mathrm{L} \\
(n=2)\end{array}$ & \\
\hline $\begin{array}{l}\text { Possible risk } \\
\text { of recurrence }\end{array}$ & $15 / 304$ & $4.9(3.0,8.0)$ & $\begin{array}{l}\text { BMI }>40 \mathrm{~kg} / \mathrm{m}^{2} \text { and weight } \\
<120 \mathrm{~kg}(n=7), \text { weight }>120 \mathrm{~kg} \\
(n=7) \text { CYP3A4 inducer }(n=1)\end{array}$ & \\
\hline $\begin{array}{l}\text { Uncertain risk } \\
\text { of recurrence }\end{array}$ & $3 / 304$ & $1.0(0.3,2.9)$ & Active malignancy ${ }^{\mathrm{c}}(n=3)$ & \\
\hline Total & $43 / 304$ & $\begin{array}{l}14.1 \\
(10.7,18.5)\end{array}$ & & \\
\hline
\end{tabular}

Abbreviations: $\mathrm{Cl}$, confidence interval; BMI, body mass index; $\mathrm{CrCl}$, creatinine clearance; $\mathrm{Gl}$, gastrointestinal.

a Patients with $>1$ prespecified risk factor were counted only once.

${ }^{\mathrm{b}} \mathrm{A}$ lower threshold of $30-40 \mathrm{~mL} / \mathrm{min}$ was considered a risk factor for bleeding as a safety precaution to allow for daily fluctuation in $\mathrm{Cr}$.

Includes patients with known/newly diagnosed malignancy at the time of VTE diagnosis.

Table 4 Secondary outcomes: clinical outcomes

\begin{tabular}{|l|l|l|l|}
\hline Outcome & Number & $\begin{array}{l}\text { Proportion \% } \\
(95 \% \mathrm{CI})\end{array}$ & Description \\
\hline Major bleeding & $1 / 304$ & $0.3(0.1,1.8)$ & Gl bleed \\
\hline CRNMB & $22 / 304$ & $7.2(4.8,10.7)$ & $\begin{array}{l}\text { Menorrhagia }(n=6), \text { Gl bleed }(n=6), \\
\text { hemoptysis }(n=3), \text { hematuria }(n=4), \text { subcutaneous hematoma }(n=2), \\
\text { bleed into ruptured Baker's cyst }(n=1)\end{array}$ \\
\hline Recurrent VTE & $3 / 304$ & $1.0(0.3,2.9)$ & Distal DVT recurrence $(n=2)$, PE $(n=1)$ \\
\hline All-cause mortality & $5 / 304$ & $1.6(0.7,3.8)$ & $\begin{array}{l}\text { Progression of metastatic cancer }(n=2),{ }^{a} \text { sepsis }(n=1), \\
\text { decompensated heart failure }(n=1), \text { cause unclear }(n=1)^{\mathrm{b}}\end{array}$ \\
\hline Rehospitalization & $22 / 304$ & $7.2(4.8,10.7)$ & Bleeding/VTE recurrence $(n=5)$, other non-VTE indications $(n=17)$ \\
\hline
\end{tabular}

Abbreviations: $\mathrm{Cl}$, confidence interval; $\mathrm{CrCl}$, creatinine clearance; CRNMB, clinically relevant nonmajor bleeding; DVT, deep vein thrombosis; GI, gastrointestinal; PE, pulmonary embolism; VTE, venous thromboembolism.

an the two patients with metastatic cancer, one was continued on rivaroxaban according to patient's preference and another was switched to enoxaparin.

${ }^{b}$ Elderly patient with PE and brain tumor on background of dementia and multiple comorbidities who was switched to apixaban in view of borderline $\mathrm{CrCl} 30-40 \mathrm{~mL} / \mathrm{min}$.

(three of five) declined. Subsequent to the heavy menstrual bleeding episode, these women chose to switch to an alternative agent (apixaban or warfarin).

\section{Feasibility of Our Nurse-Led Postdischarge Pathway}

Our experience with this nurse-led pathway suggests that it is easy to implement, requiring minimal resources and personnel (one nurse and access to support from two to three specialist hematologists as required). Most of our interventions (153 of $167,90 \%$ ) were minor, including those used ( 34 of $40,85 \%$ ) to address prespecified major risk factors for bleeding or recurrence. By using readily available and inexpensive communication tools such as telephone and text messaging, we were able to minimize travel time and expenses for both clinicians and patients while enabling follow-up to be kept on schedule, thus allowing for timely contact and intervention if required.

\section{Strengths and Limitations}

Our study has several strengths. First, our cohort consists of consecutive patients in a large university hospital setting, and is thus representative of "real-world" patients. We used prespecified criteria to identify patients at risk of bleeding/ VTE recurrence for which an intervention was indicated, thus limiting case-finding bias and to ascertain our primary and secondary outcomes. All patients were prospectively 
Table 5 Comparison of clinical outcomes in randomized trials and routine clinical practice studies

\begin{tabular}{|c|c|c|c|c|c|}
\hline Study & Patients, $n$ & $\begin{array}{l}\text { Major } \\
\text { bleeding, \% }\end{array}$ & CRNMB, \% & $\begin{array}{l}\text { Recurrent } \\
\text { VTE, \% }\end{array}$ & Length of follow-up, $d$ \\
\hline Einstein acute DVT study ${ }^{5}$ & 1731 & 0.8 & 7.3 & 2.1 & Range $90-360^{\mathrm{a}}$ \\
\hline Einstein PE study ${ }^{6}$ & 2419 & 1.1 & 9.5 & 2.1 & Mean $270^{\text {a }}$ (range $90-360$ ) \\
\hline DRESDEN registry ${ }^{21}$ & 575 & $4.1^{\mathrm{b}}$ & $17.2 \dagger$ & NA & Median $274^{\mathrm{a}}$ \\
\hline Swivter ${ }^{22}$ & 417 & 0.5 & NA & 1.2 & 90 \\
\hline Danish Registry ${ }^{23}$ & 5411 & 2.3 & NA & 3.1 & 180 \\
\hline $\begin{array}{l}\text { Danish Registry24 } \\
\text { (unprovoked VTE) }\end{array}$ & 1734 & $2.4^{\mathrm{b}}$ & NA & $9.9^{\mathrm{b}}$ & 180 \\
\hline XALIA $^{25}$ & 2619 & $\begin{array}{l}0.7 \\
1.2^{\mathrm{b}}\end{array}$ & NA & 1.4 & Median 239 (IQR 154,388) \\
\hline REMOTEV $^{26}$ & 280 & 1.1 & 4.4 & 1.4 & 180 \\
\hline $\begin{array}{l}\text { U.S. retrospective } \\
\text { Claims database analysis }\end{array}$ & 13609 & 0.8 & NA & 2.8 & Mean 180 \\
\hline $\begin{array}{l}\text { Current study } \\
\text { (prospective cohort) }\end{array}$ & 304 & 0.3 & 7.2 & 1.0 & 90 \\
\hline
\end{tabular}

Abbreviations: CRNMB, clinically relevant nonmajor bleeding; DVT, deep vein thrombosis; IQR, interquartile range; NA, not available.

${ }^{a}$ Treatment duration is used because data on length of follow-up are not provided (patients were followed up for a minimum of time on anticoagulant treatment).

${ }^{\mathrm{b}}$ Expressed as per 100 patient years.

followed up as part of the pathway to the end of their course of anticoagulation or up to 90 days, thus minimizing bias introduced by loss to follow-up.

There are several limitations to our study. First, there was no comparator group; however, we showed that our clinical outcome data are comparable to phase 3 clinical trials and XALIA where patients were managed by experienced staff and were closely monitored. The low rates of bleeding in our study are likely biased by only including patients and the corresponding events that occurred post discharge when patients were identified in the pathway. However, this was the intended purpose of our study and despite this, a significant number of patients were still identified to be at major risk for bleeding or recurrence post discharge. Six patients had CRNMB between hospital discharge and first contact, all of which were reported to the nurse. Of these patients, major interventions were initiated in three patients: two had unscheduled clinic review and one patient was asked to present to emergency. While it is possible that some adverse events between discharge and the initial contact (day $12 \pm 4$ from initiation of rivaroxaban) may have occurred and were not reported, we are confident that these data would have been captured as all patients were specifically asked by the nurse about any bleeding or symptoms of recurrence according to our prespecified checklist (-Supplementary Fig. S2, online only) and this was verified by checking the electronic medical records for any hospital presentations which may have occurred.

\section{Conclusion}

A nurse-led pathway for early postdischarge review and monitoring of patients with acute VTE initiated on rivarox- aban identified one in seven patients with VTE discharged on rivaroxaban who were at major or possible risk of bleeding or recurrence. Early identification and appropriate interventions in these patients likely contributed to the overall low rates of major bleeding and VTE recurrence in the entire cohort. Our experience highlights the feasibility and the potential benefits of an early nurse-led clinical surveillance pathway for patients with acute VTE starting NOAC therapy.

\section{Contributions}

S. Chunilal and A. Cummins were involved in the conception and design of the project. M.S. Lim, T. Indran, and A.Cummins were involved in data acquisition. M.S. Lim, S. Chunilal, and N. C. Chan were involved in data analysis and interpretation. M. S. Lim wrote the first draft of the manuscript. All authors contributed to critical revision of the manuscript and approved the final version of the manuscript.

\section{Conflict of Interests}

T. Indran and A. Bennett received honorarium from Bayer during the conduct of the study. S. Chunilal received honorarium and consultancy fees from Bayer during the conduct of the study. $\mathrm{H}$. Tran received honorarium from Bayer, Pfizer, Bristol Myers Squibb, and Boehringer Ingelheim unrelated to the conduct of the study. N.C. Chan received honorarium from Bayer outside the submitted work. All other authors declare no conflict of interests.

\section{Acknowledgments}

The study was supported by a sponsorship provided by Bayer Australia Limited (Bayer) to Monash Health. Bayer had no involvement in the study design; data collection, analysis, or interpretation; or writing of the manuscript. 


\section{References}

1 Cushman M. Epidemiology and risk factors for venous thrombosis. Semin Hematol 2007;44(02):62-69

2 van Es N, Coppens M, Schulman S, Middeldorp S, Büller HR. Direct oral anticoagulants compared with vitamin $\mathrm{K}$ antagonists for acute venous thromboembolism: evidence from phase 3 trials. Blood 2014;124(12):1968-1975

3 Pratt NL, Ramsay EN, Caughey GE, Shakib S, Roughead EE. Uptake of novel oral anticoagulants in Australia. Med J Aust 2016;204 (03):104-5.e1

4 Shehab N, Lovegrove MC, Geller AI, Rose KO, Weidle NJ, Budnitz DS. US emergency department visits for outpatient adverse drug events, 2013-2014. JAMA 2016;316(20):2115-2125

5 Bauersachs R, Berkowitz SD, Brenner B, et al; EINSTEIN Investigators. Oral rivaroxaban for symptomatic venous thromboembolism. N Engl J Med 2010;363(26):2499-2510

6 Büller HR, Prins MH, Lensin AWA, et al; EINSTEIN-PE Investigators. Oral rivaroxaban for the treatment of symptomatic pulmonary embolism. N Engl J Med 2012;366(14):1287-1297

7 Agnelli G, Buller HR, Cohen A, et al; AMPLIFY Investigators. Oral apixaban for the treatment of acute venous thromboembolism. $\mathrm{N}$ Engl J Med 2013;369(09):799-808

8 Schulman S, Kearon C, Kakkar AK, et al; RE-COVER Study Group. Dabigatran versus warfarin in the treatment of acute venous thromboembolism. N Engl J Med 2009;361(24):2342-2352

9 Schulman S, Kakkar AK, Goldhaber SZ, et al; RE-COVER II Trial Investigators. Treatment of acute venous thromboembolism with dabigatran or warfarin and pooled analysis. Circulation 2014;129 (07):764-772

10 Büller HR, Décousus H, Grosso MA, et al; Hokusai-VTE Investigators. Edoxaban versus warfarin for the treatment of symptomatic venous thromboembolism. N Engl J Med 2013;369(15):1406-1415

11 Larock A-S, Mullier F, Sennesael A-L, et al. Appropriateness of prescribing dabigatran etexilate and rivaroxaban in patients with nonvalvular atrial fibrillation: a prospective study. Ann Pharmacother 2014;48(10):1258-1268

12 Chowdhry U, Jacques A, Karovitch A, Giguère P, Nguyen M-L. Appropriateness of dabigatran and rivaroxaban prescribing for hospital inpatients. Can J Hosp Pharm 2016;69(03):194-201

13 Tellor KB, Patel S, Armbruster AL, Daly MW. Evaluation of the appropriateness of dosing, indication and safety of rivaroxaban in a community hospital. J Clin Pharm Ther 2015;40(04):447-451

14 Pattullo CS, Barras M, Tai B, McKean M, Donovan P. New oral anticoagulants: appropriateness of prescribing in real-world setting. Intern Med J 2016;46(07):812-818

15 Ageno W, Crowther M, Baglin T, Falanga A, Buller H, Palareti G; Subcommittee on Control of Anticoagulation of the Scientific and Standardization Committee of the International Society on Thrombosis and Haemostasis. Selection and assessment of patients treated with the novel oral anticoagulant drugs: a recommendation from the Subcommittee on Control of Anticoagulation of the Scientific and Standardisation Committee of the International Society on Thrombosis and Haemostasis. J Thromb Haemost 2013;11(01):177-179

16 Heidbuchel H, Verhamme P, Alings M, et al; European Heart Rhythm Association. European Heart Rhythm Association Practical Guide on the use of new oral anticoagulants in patients with non-valvular atrial fibrillation. Europace 2013;15(05):625-651
17 Heidbuchel H, Berti D, Campos M, et al. Implementation of nonvitamin $\mathrm{K}$ antagonist oral anticoagulants in daily practice: the need for comprehensive education for professionals and patients. Thromb J 2015;13:22

18 Schulman S, Kearon C; Subcommittee on Control of Anticoagulation of the Scientific and Standardization Committee of the International Society on Thrombosis and Haemostasis. Definition of major bleeding in clinical investigations of antihemostatic medicinal products in non-surgical patients. J Thromb Haemost 2005;3(04):692-694

19 Kaatz S, Ahmad D, Spyropoulos AC, Schulman S; Subcommittee on Control of Anticoagulation. Definition of clinically relevant nonmajor bleeding in studies of anticoagulants in atrial fibrillation and venous thromboembolic disease in non-surgical patients: communication from the SSC of the ISTH. J Thromb Haemost 2015;13(11):2119-2126

20 Condliffe R. Pathways for outpatient management of venous thromboembolism in a UK centre. Thromb J 2016;14(01):47

21 Beyer-Westendorf J, Förster K, Pannach S, et al. Rates, management, and outcome of rivaroxaban bleeding in daily care: results from the Dresden NOAC registry. Blood 2014;124(06):955-962

22 Kucher N, Aujesky D, Beer JH, et al. Rivaroxaban for the treatment of venous thromboembolism. The SWIss Venous ThromboEmbolism Registry (SWIVTER). Thromb Haemost 2016;116(03):472-479

23 Sindet-Pedersen C, Langtved Pallisgaard J, Staerk L, et al. Comparative safety and effectiveness of rivaroxaban versus VKAs in patients with venous thromboembolism. A Danish nationwide registrybased study. Thromb Haemost 2017;117(06):1182-1191

24 Larsen TB, Skjøth F, Kjældgaard JN, Lip GYH, Nielsen PB, Søgaard M. Effectiveness and safety of rivaroxaban and warfarin in patients with unprovoked venous thromboembolism: a propensity-matched nationwide cohort study. Lancet Haematol 2017;4(05):e237-e244

25 Ageno W, Mantovani LG, Haas S, et al. Safety and effectiveness of oral rivaroxaban versus standard anticoagulation for the treatment of symptomatic deep-vein thrombosis (XALIA): an international, prospective, non-interventional study. Lancet Haematol 2016;3(01):e12-e21

26 Gaertner S, Cordeanu E-M, Nouri S, et al. Rivaroxaban versus standard anticoagulation for symptomatic venous thromboembolism (REMOTEV observational study): analysis of 6-month outcomes. Int J Cardiol 2017;226:103-109

27 Coleman CI, Bunz TJ, Turpie AGG. Effectiveness and safety of rivaroxaban versus warfarin for treatment and prevention of recurrence of venous thromboembolism. Thromb Haemost 2017;117(10):1841-1847

28 Tran E, Duckett A, Fisher S, Bohm N. Appropriateness of direct oral anticoagulant dosing for venous thromboembolism treatment. J Thromb Thrombolysis 2017;43(04):505-513

29 Trujillo-Santos J, Di Micco P, Dentali F, et al; RIETE Investigators. Real-life treatment of venous thromboembolism with direct oral anticoagulants: the influence of recommended dosing and regimens. Thromb Haemost 2017;117(02):382-389

30 De Crem N, Peerlinck K, Vanassche T, et al. Abnormal uterine bleeding in VTE patients treated with rivaroxaban compared to vitamin K antagonists. Thromb Res 2015;136(04):749-753

31 Martinelli I, Lensing AWA, Middeldorp S, et al. Recurrent venous thromboembolism and abnormal uterine bleeding with anticoagulant and hormone therapy use. Blood 2016;127(11):1417-1425 